\title{
ANALISA PRODUKTIVITAS DAN BIAYA OPERASIONAL ALAT BERAT PADA PROYEK PEMBANGUNAN STREET-RACE CIRCUIT MANDALIKA
}

\author{
HASYIM $^{1)}$, I GEDE PUTU WARKA ${ }^{2)}$, CAHYA PURI ARIATI' \\ JURUSAN TEKNIK SIPIL UNIVERSITAS MATARAM
}

e-mail:hasyim_husien@unram.ac.id

\begin{abstract}
ABSTRAK
Proyek sirkuit Mandalika merupakan proyek konstruksi berskala besar yang dibangun di Kawasan Ekonomi Khusus (KEK) Pariwisata Mandalika Lombok Tengah Nusa Tenggara Barat (NTB). Srikuit sepanjang 4.31 kilometer ini memiliki 19 tikungan. Analisa dilakukan untuk mendapatkan produktivitas alat berat, biaya operasional alat berat, pendapatan dan profit dari alat berat Excavator, Dump Truck, Motor Grader, Vibrating Roller dan Water Tank di lapangan.

Analisa produktivitas alat-alat berat Pekerjaan galian struktur kedalaman 2-4 meter yaitu excavator sebesar $17,778 \mathrm{~m}^{3} / \mathrm{jam}$ dan dump truck sebesar $11,755 \mathrm{~m}^{3} / \mathrm{jam}$. Untuk pekerjaan timbunan biasa dari sumber galian produksi yang dihasilkan oleh excavator sebesar $30,521 \mathrm{~m}^{3} / \mathrm{jam}$, dump truck sebesar $13,171 \mathrm{~m}^{3} / \mathrm{jam}$, motor grader sebesar $1.839,780 \mathrm{~m}^{3} / \mathrm{jam}$, vibrator roller sebesar $90,414 \mathrm{~m}^{3} / \mathrm{jam}$ dan water tanker truck sebesar $71,142 \mathrm{~m}^{3} / \mathrm{jam}$. Sedangkan untuk pekerjaan penyiapan badan jalan produksi yang dihasilkan oleh motor grader sebesar $362,222 \mathrm{~m}^{3} / \mathrm{jam}$, vibrator roller sebesar $126,851 \mathrm{~m}^{3} / \mathrm{jam}$ dan water tanker truck sebesar $62,250 \mathrm{~m}^{3} / \mathrm{jam}$. Biaya operasi per jam untuk alat berat excavator sebesar Rp. 718.048,581. Untuk alat berat motor grader didapatkan biaya operasi per jam sebesar Rp. 670.416,081. Vibrator roller sebesar Rp. 609.423,907. Sedangkan untuk water tanker truck diperoleh biaya operasi sebesar Rp. 380.806,081. Pendapatan dan profit yang didapatkan dari penggunaan alat berat pada pekerjaan tanah proyek sirkuit Mandalika adalah Rp. 39.488.806.755 dan Rp. 3.589.981.523,05.
\end{abstract}

Kata kunci: Alat berat, produktivitas per jam, biaya operasional

\section{ABSTRACT}

The Mandalika circuit project is a large-scale construction project built in the Mandalika Special Economic Zone (SEZ), Central Lombok, West Nusa Tenggara (NTB). The 4.31 kilometer racetrack will have 19 bends, so it requires heavy equipment to improve the quality production and increase project efficiency. The analysis conducted to obtain the hourly productivity, operating cost, income and profit of excavators, dump trucks, motor grader, vibrator roller, and water tanker used in the worksite of Mandalika circuit.

The hourly productivity for structural cut with a depth of 2 to 4 meter of excavator is $17.778 \mathrm{~m} / \mathrm{h}$ and dump truck $11.755 \mathrm{~m} 3 / \mathrm{h}$. The excavator production for stockpiling from excavated sources is 30.521 $m 3 / h$, dump truck $13.171 \mathrm{~m}^{3} / \mathrm{h}$, motor graders $1839.780 \mathrm{~m}^{3} / \mathrm{h}$, vibrator roller $90.414 \mathrm{~m}^{3} / \mathrm{h}$ and water tankers truck $71,142 \mathrm{~m} 3 / \mathrm{h}$. Motor grader production for road body preparation work is 362,222 $\mathrm{m} 3 / \mathrm{h}$, vibrator roller $126,851 \mathrm{~m} 3 / \mathrm{h}$ and water tanker truck $62,250 \mathrm{m3} / \mathrm{h}$. The hourly operating cost for the excavator is Rp. 718,048,581, motor grader Rp. 670,416,081, vibrator roller Rp. 609,423,907, and water tanker truck $R p$. 380,806,081. The income and profit from the use of heavy equipment are Rp. 39,488,806,755 and Rp. 3,589,981,523.05.

Keywords: Heavy equipment, hourly productivity, operating cost

\section{PENDAHULUAN}

Dewasa ini pertumbuhan penduduk di Lombok terus berkembang pesat, sehingga menyebabkan peningkatan kebutuhan akan konstruksi sipil. Oleh sebab itu diperlukan langkah-langkah yang tepat, baik dalam perencanaan maupun dalam pelaksanaan sehingga sumber daya yang ada dapat digunakan seoptimal mungkin. 
Secara umum suatu proyek konstruksi dapat dikatakan sebagai suatu rangkaian kegiatan yang berkaitan dengan upaya pembangunan suatu bangunan, mencakup pekerjaan pokok dalam bidang teknik sipil dan arsitektur. Proyek konstruksi dilaksanakan serta diselesaikan dalam jangka waktu terbatas dengan sumber daya tertentu untuk mencapai suatu hasil konstruksi dengan standar kualitas baik. Dalam hal ini alat berat memiliki faktor penting di dalam proyek, terutama proyek-proyek konstruksi maupun pertambangan dan kegiatan lainnya dalam skala yang besar. Tujuan dari penggunan alat berat tersebut adalah untuk memudahkan manusia dalam mengerjakan pekerjaannya, sehingga hasil yang diharapkan dapat tercapai dengan lebih mudah dengan waktu yang relatif lebih singkat (rochmanhadi, 1985). Walaupun penggunaan alat berat sangat berpengaruh pada progres kemajuan suatu kegiatan pekerjaan, kemampuan dalam memperhatikan, memilih dan menggunakan alat berat sangat diperlukan. Wilopo (2011), pemilihan dan pengendalian alat berat adalah proses merencanakan, mengorganisir, memimpin dan mengendaliakan alat berat untuk mencapai tujuan pekerjaan yang ditentukan.

Perencanaan matang dalam pemilihan jenis dan jumlah alat berat serta metode pelaksanaan yang akan digunakan suatu proyek harus sesuai dengan fungsi, guna, medan kerja, kondisi peralatan, dan kondisi pemeliharaan. Di Indonesia terdapat beberapa merek dan tipe alat berat. Masing-masing merek dan tipe dari jenis alat berat tersebut tentulah mempunyai kelebihan dan kekurangannya pada setiap produk alat berat yang mereka keluarkan. Para kontraktor harus jeli dalam memilih alat berat yang akan digunakan guna meningkatkan efisiensi dan efektifitas pada pekerjaan yang akan dilakukan.

Hal lain yang juga penting untuk diperhatikan adalah kemampuan mengestimasi biaya-biaya alat berat yang akan dikeluarkan. Penguasaan tentang penentuan komponen-komponen harga yang berpengaruh pada alat berat tidak semudah yang dilihat di lapangan. Banyak faktor yang mempengaruhi hal tersebut baik dari segi teknis maupun non teknis. Dengan mengetahui biaya operasi (operating cost) akan dapat membantu mengetahui keuntungan yang bisa diperoleh setelah menyelesaikan suatu pekerjaan. Dengan pencatatan yang akurat atas biaya operasi peralatan juga akan membantu dalam perhitungan perencanaan biaya pekerjaan berikutnya. Kesalahan dalam pemilihan alat berat dan penggunaannya yang kurang tepat dengan kondisi dan situasi lapangan pekerjaan akan mempengaruhi produktivitas alat berat dan tidak tercapainya jadwal atau target yang telah ditentukan, dengan demikian akan terjadi penambahan biaya pekerjaan yang cukup besar.

Proyek pembangunan Street-Race Circuit (Sirkuit Jalan Raya) pertama di Indonesia yang dibangun di Kawasan Ekonomi Khusus (KEK) Pariwisata Mandalika, Lombok Tengah, Nusa Tenggara Barat (NTB) adalah pembangunan yang diharapkan dapat memberikan dampak ekonomi yang besar bagi masyarakat serta dapat meningkatkan awareness mengenai pengembangan sebuah kawasan pariwisata kelas dunia dan penciptaan lapangan pekerjaan di Mandalika. Sirkuit Mandalika akan dibangun sepanjang 4.31 kilometer dengan total 19 tikungan dan bersifat sirkuit tidak permanen yang mana artinya setelah selesai balapan, sirkuit bisa digunakan untuk jalan raya. Proses pembangunan sirkuit Mandalika terus berlangsung ditengah merebaknya pandemi virus Corona dan berjalan normal sesuai timeline yang direncanakan serta ditargetkan selesai sesuai jadwal yaitu akhir tahun 2020. BUMN pengembangan kawasan pariwisata The Nusa Dua, Bali dan The Mandalika, NTB menyatakan pekerjaan tanah merupakan salah satu bagian penting dari konstruksi sirkuit Mandalika guna menjadikan sirkuit Mandalika sesuai dengan regulasi dan standar dari Federation Internationale de Motocyclisme (FIM). Oleh karena itu kontraktor pelaksana harus cermat dalam memperhitungkan unit pekerjaan demi tercapainya pekerjaan yang selesai tepat waktu.

Dari permasalahan di atas, maka penulis ingin menganalisis dan mengetahui produktivitas alat berat serta biaya operasional alat berat pada proyek pembangunan sirkuit mandalika yang sesuai dengan jumlah volume pekerjaan agar peralatan dapat bekerja sesuai dengan jumlah jam kerja yang ada sehingga diharapkan hal tersebut dapat menunjang kelancaran proyek baik untuk tiap pekerjaan maupun pekerjaan secara keseluruhan.

\section{Rumusan Masalah}

Dari uraian di atas, rumusan masalah pada penelitian ini yaitu :

1. Berapakah produktivitas alat-alat berat pada pekerjaan tanah proyek Street-Race Circuit di Mandalika Lombok Tengah, Nusa Tenggara Barat (NTB)?

2. Berapakah kebutuhan alat-alat berat pada pekerjaan tanah proyek Street-Race Circuit di Mandalika Lombok Tengah, Nusa Tenggara Barat (NTB)?

3. Berapakah biaya operasional alat-alat berat pada pekerjaan tanah proyek Street-Race Circuit di Mandalika Lombok Tengah, Nusa Tenggara Barat (NTB)?

4. Berapakah pendapatan serta profit yang didapatkan dari penggunaan alat berat pada pekerjaan tanah proyek Street-Race Circuit di Mandalika Lombok Tengah, Nusa Tenggara Barat (NTB)? 


\section{Tujuan Penelitian}

Penelitian ini bertujuan untuk :

1. Menganalisa produktivitas dari alat-alat berat pada pekerjaan tanah proyek Street-Race Circuit di Mandalika, Lombok Tengah, Nusa Tenggara Barat (NTB).

2. Mengetahui jumlah kebutuhan alat-alat berat pada pekerjaan tanah proyek Street-Race Circuit di Mandalika, Lombok Tengah, Nusa Tenggara Barat (NTB).

3. Mengetahui besaran biaya operasional masing-masing alat berat, khususnya pada pekerjaan tanah di proyek Street-Race Circuit di Mandalika, Lombok Tengah, Nusa Tenggara Barat (NTB).

4. Mengetahui pendapatan dan profit yang didapatkan dari penggunaan alat berat pada pekerjaan tanah di proyek Street-Race Circuit di Mandalika, Lombok Tengah, Nusa Tenggara Barat (NTB).

\section{Manfaat Penelitian}

Manfaat dari penelitian ini adalah :

1. Menambah wawasan peneliti mengenai produktivitas dan optimalisasi pengelolaan serta pemanfaatan alat berat pada pengerjaan proyek pembangunan sirkuit jalan raya.

2. Mengetahui besaran biaya operasional alat-alat berat pada pekerjaan tanah proyek pembangunan sirkuit jalan raya Mandalika.

3. Menambah referensi bagi pembaca tentang wacana manajemen proyek alat berat, pengelolaan dan pemanfaatan yang lebih baik pada pekerjaan sipil sesuai dengan tujuan penelitian dalam kasus ini.

\section{METODE PENELITIAN}

Analisis pada penelitian ini yaitu analisis mengenai topik yang menyangkut tentang alat berat, pada pekerjaan sipil di bidang pematangan lahan, baik pekerjaan galian, timbunan maupun pemadatan tanah pada lokasi yang ditinjau yaitu Ruas Vinci yang merupakan ruas proyek pebangunan Street-Race Circuit di Mandalika. Analisis yang akan dilakukan yaitu perhitungan produktivitas, biaya operasi, pendapatan dan profit alat berat yang digunakan, yaitu : Excavator, Dump Truck, Motor Grader, Vibrator Roller, Water Tank.

\section{Produksi Alat Berat dan Kebutuhan Alat Berat}

Menurut Sokop RM, dkk (2018), produktivitas atau kapasitas alat adalah besarnya keluaran (output) volume pekerjaan tertentu yang dihasilkan alat per-satuan waktu. Untuk memperkirakan produktivitas alat diperlukan faktor standar kinerja alat yang diberikan oleh pabrik pembuat alat, faktor efisiensi alat, operator, kondisi lapangan dan material. Dalam menentukan durasi suatu pekerjaan maka hal-hal yang perlu diketahui adalah volume pekerjaan dan produktivitas alat tersebut. Produktivitas adalah perbandingan antara hasil yang dicapai dengan seluruh sumber daya yang digunakan (Rostiyanti, 2002). Untuk menghitung durasi pekerjaan dapat menggunakan persamaan :

$$
\text { Durasi }=\frac{\text { Volume Pekerjaan }}{\text { Kapasitas Produksi Alat }}
$$

Kebutuhan peralatan adalah jumlah jumlah peralatan yang digunakan pada setiap uraian pekerjaan agar dapat bekerja efektif sesuai dengan jumlah jam kerja yang ada dan dapat menghasilkan volume pekerjaan sesuai dengan uraian pekerjaan yang ada. Untuk menghitung kebutuhan alat berat dapat menggunakan persamaan :

\section{Excavator / Backhoe}

$$
\text { Kebutuhan alat berat }=\frac{\text { Volume Pekerjaan }}{\text { kapasitas produksi } x \text { durasi }}
$$

Produktivitas backhoe lexcavator dinyatakan dengan persamaan :

$$
Q=\frac{V x F b x F a x 60 x F k}{T s x F v}
$$

dimana :

$\mathrm{Q} \quad=$ produksi per jam (m /jam);

$\mathrm{V} \quad=$ kapasitas bucket $(\mathrm{m})$;

$\mathrm{F}_{\mathrm{b}} \quad$ = faktor bucket backhoe /excavator;

$\mathrm{F}_{\mathrm{a}}=$ faktor efisiensi alat (ambil kondisi kerja paling baik, 0.83); $\mathrm{F}_{\mathrm{v}} \quad=$ faktor konversi (kedalaman < $40 \%)$;

$\mathrm{T}_{\mathrm{s}} \quad=$ waktu siklus (menit).

(sumber : Pedoman AHSP, Kementrian PU. 2016) 


\section{Dump Truck}

Produktivitas dump truck dinyatakan dengan persamaan :

$$
Q=\frac{V \times F a x 60}{D \times T s}
$$

dimana :

$\mathrm{Q}=$ produksi per jam (m/jam);

$\mathrm{F}_{\mathrm{a}}=$ faktor efisiensi alat;

$\mathrm{D}=$ berat isi material (lepas, gembur) (ton $/ \mathrm{m}$ )

(sumber : Pedoman AHSP, Kementrian PU. 2016)
$\mathrm{V} \quad=$ kapasitas dump truck (m );

$\mathrm{T}_{\mathrm{s}} \quad=$ waktu siklus dump truck;

\section{Motor Grader}

Produktivitas motor grader dinyatakan dengan persamaan : Untuk pekerjaan perataan hamparan :

$$
Q=\frac{\operatorname{Lh} x\{n(b-b 0)+b 0\} \times F a \times 60}{N \times n \times T s}
$$

dimana :

$\begin{array}{lll}\mathrm{Q} & =\text { kapasitas produksi jam }(\mathrm{m} / \mathrm{jam}) ; & \mathrm{L}_{\mathrm{h}}=\text { panjang }(\mathrm{m}) ; \\ \mathrm{V} & =\text { kecepatan kerja }(\mathrm{km} / \mathrm{jam}) ; & \mathrm{b}_{0}=\text { lebar tumpang tindih/overlap }(\mathrm{m}) ; \\ \mathrm{F}_{\mathrm{a}} & =\text { faktor efisiensi kerja } & \mathrm{n}=\text { jumlah lintasan; } \\ \mathrm{N} & =\text { jumlah pengupasan tiap lintasan; } & \mathrm{v}=\text { kecepatan rata-rata }(\mathrm{km} / \mathrm{jam}) ; \\ \mathrm{b} & =\text { lebar pisau efektif }(\mathrm{m}) ; & \mathrm{T}_{1}=\text { waktu 1 kali lintasan : (Lh x 60)/ } \\ \mathrm{T}_{2} & =\text { lain-lain (menit); } & \text { (v x 1000) (menit); } \\ \mathrm{T}_{\mathrm{S}} & =\text { waktu siklus (menit). Untuk pekerjaan hamparan padat : }\end{array}$

$\mathrm{F}_{\mathrm{k}} \quad=$ faktor pengembangan bahan;

$$
Q=\frac{\operatorname{Lh} \times\{n(b-b 0)+b 0\} \times F a \times 60 \times t}{N \times n \times T s \times F k}
$$

dimana :

$\mathrm{t}=$ tebal hamparan padat (diambil $0.15 \mathrm{~m}$ ). Untuk pekerjaan pengupasan (grading):

$$
Q=\frac{\operatorname{Lh} x\{n(b-b 0)+b 0\} \times s F a \times 6 C}{N \times n \times T s}
$$

dimana :

$\mathrm{Q} \quad=$ kapasitas produksi jam (m/jam);

$\mathrm{L}_{\mathrm{h}}=$ panjang $(\mathrm{m})$;

$\mathrm{V} \quad=$ kecepatan $\mathrm{kerja}(\mathrm{km} / \mathrm{jam})$;

$\mathrm{b}_{0}=$ lebar tumpang tindih/overlap $(\mathrm{m})$;

$\mathrm{F}_{\mathrm{a}} \quad=$ faktor efisiensi kerja

$\mathrm{N} \quad$ = jumlah pengupasan tiap lintasan;

$\mathrm{n}=$ jumlah lintasan;

b lebar pisau efektif (m);

$\mathrm{v}=$ kecepatan rata-rata $(\mathrm{km} / \mathrm{jam})$;

$\mathrm{T}_{1} \quad$ = waktu 1 kali lintasan : (Lh x 60) / ( $\mathrm{v}$ x 1000) (menit); $\mathrm{T}_{2}=$ lain-lain (menit);

$\mathrm{T}_{\mathrm{S}} \quad=$ waktu siklus (menit).

(sumber : Pedoman AHSP, Kementrian PU. 2016)

Vibrator Roller

Produktivitas vibrator roller dinyatakan dengan persamaan :

dimana :

$$
Q=\frac{(b e \times v \times 1000) x+x F a}{n}
$$

$\mathrm{b}_{\mathrm{e}}=$ lebar efektif pemadatan $=\mathrm{b}-\mathrm{b} 0($ overlap $)(\mathrm{m}) ; \mathrm{b} \quad=$ lebar efektif pemadatan; $(1,680 \mathrm{~m})(\mathrm{m}) ;$

$\mathrm{b}_{\mathrm{O}}=$ lebar overlap; $(0,20 \mathrm{~m})(\mathrm{m}) ; \mathrm{t} \quad=$ tebal pemadatan $(\mathrm{m})$;

$\mathrm{v}=$ kecepatan rata-rata alat; (diambil 4,0 km/jam) $(\mathrm{km} / \mathrm{jam}) ; \mathrm{n}=$ jumlah lintasan; (diambil 8 lintasan) (lintasan);

$\mathrm{Fa}=$ faktor efisiensi alat; diambil 0,83 (kondisi baik).

(sumber : Pedoman AHSP, Kementrian PU. 2016) 


\section{Water Tanker}

Produktivitas water tanker dinyatakan dengan persamaan :

$$
Q=\frac{P a \times F a \times 60}{W c \times 1000}
$$

dimana :

$\mathrm{Q}=$ produksi alat per jam $\left(\mathrm{m}^{3} / \mathrm{jam}\right)$;

$\mathrm{P}_{\mathrm{a}}=$ kapasitas pompa air (diambil $100 \mathrm{l} / \mathrm{menit}$ ); $\mathrm{W}_{\mathrm{c}}=$ kebutuhan air $/ \mathrm{m}^{3}$ material padat;

$\mathrm{F}_{\mathrm{a}}=$ Faktor efisiensi alat

$\mathrm{V}=$ volume tangka air $\left(\mathrm{m}^{3}\right)$.

(sumber : Pedoman AHSP, Kementrian PU. 2016)

\section{Analisa Biaya Alat}

Biaya Kepemilikan

Biaya kepemilikan adalah jumlah biaya dalam rupiah yang harus diterima kembali oleh pemilik alat karena telah mengeluarkan biaya untuk pembelian alat, angkutan, pajak, asuransi, setiap jam selama umur ekonomis alat. Bunga modal juga harus diterima pemilik alat setiap jam selama umur ekonomis alat. Biaya kepemilikan terdiri dari :

a. Biaya penyusutan (Depresiasi)

Jangka waktu penyusutan biasanya diberikan oleh pabrik pembuat sesuai jenis alat dan kondisi kerja.

b. Bunga modal, pajak dan asuransi

Besarnya suku bunga disesuaikan dengan suku bunga yang berlaku (Pedoman AHSP, Kementerian PU. 2016).

Nilai sisa alat $=10 \% \times$ Harga alat

Biaya bunga yang berlaku (bunga modal) dapat dihitung dengan :

Biaya pengembalian modal dihitung dengan :

$$
\text { Bunga Modal }=\frac{i x(1+i)^{A}}{(1+i)^{A}-1}
$$

$=\frac{\text { (harga alat-nilai sisa alat) } x \text { bunga moda }}{\text { jam } \text { kerja dalam satu tahun }}$

Biaya asuransi, dll dihitung dengan :

$$
=\frac{0.002 \times \text { harga alat }}{\text { jam kerja dalam satu tahum }}
$$

Sehingga : $\quad$ Biaya pasti perjam $=$ biaya pengembalian modal + asuransi

\section{Biaya Operasi Alat}

Biaya operasi adalah biaya-biaya yang dikeluarkan untuk keperluan-keperluan pengoprasian alat, yang terdiri dari biaya-biaya :

\section{Biaya bahan bakar $(\mathbf{H})$}

Banyaknya bahan bakar per jam yang digunakan oleh mesin penggerak dan tergantung pada besarnya kapasitas tenaga mesin, biasanya diukur dengan satuan HP (Horse Power) (Pedoman AHSP, Kementerian PU. 2016).

$$
H=(12,00 \mathrm{~s} / \mathrm{d} 15,00) \% \times \mathrm{HP}
$$

dimana :

$\mathrm{H} \quad=$ bahan bakar yang dipergunakan dalam 1 jam (liter/jam);

$\mathrm{HP} \quad=$ horse Power, kapasitas tenaga mesin penggerak;

$12,00 \%=$ untuk alat yang bertugas ringan;

$15,00 \%=$ untuk alat yang bertugas berat.

\section{Biaya Pelumas (I)}

Banyaknya minyak pelumas (termasuk pemakaian minyak yang lain serta grease) yang dipergunakan oleh peralatan yang bersangkutan dihitung dengan rumus dan berdasarkan kapasitas tenaga mesin (Pedoman AHSP, Kementerian PU. 2016). 
dimana :

$$
l=(2,5 \mathrm{~s} / \mathrm{d} 3) \% \times \mathrm{HP}
$$

I = banyaknya minyak pelumas yang dipakai dalam 1 (liter / jam);

HP = kapasitas tenaga mesin (Horse Power);

$2.5 \%=$ untuk pemakaian ringan;

$3 \%=$ untuk pemakaian berat.

\section{Biaya Perbaikan (K)}

Untuk menghitung biaya perbaikan termasuk penggantian suku cadang yang aus (Pedoman AHSP, Kementerian PU. 2016).

dimana :

$$
\mathrm{K}=(12,5 \mathrm{~s} / \mathrm{d} 17,5) \% \times \mathrm{B} / \mathrm{W}
$$

$\mathrm{B} \quad=$ harga pokok alat setempat;

$\mathrm{W}=$ jumlah jam kerja alat dalam satu tahun;

$12.5 \%=$ untuk pemakaian ringan;

$17.5 \%=$ untuk pemakaian berat.

\section{Biaya Bengkel (J)}

Besarnya biaya bengkel (workshop) tiap jam dihitung sebagai berikut (Pedoman AHSP, Kementerian PU. 2016) :

dimana :

$$
\mathrm{J}=(6,25 \mathrm{~s} / \mathrm{d} 8,75) \% \times \mathrm{B} / \mathrm{W}
$$

$\mathrm{b} \quad=$ harga pokok alat setempat;

$\mathrm{W}=$ jumlah jam kerja alat dalam satu tahun;

$6.25 \%=$ untuk pemakaian ringan;

$8.75 \%=$ untuk pemakaian berat.

\section{Upah Operator (L) dan Pembantu Operator (M)}

Upah Operator dan Pembantu operator atau driver, dihitung dengan persamaan (Pedoman AHSP, Kementerian PU. 2016) :

Operator $(\mathrm{L}) \quad=(1$ orang $/ \mathrm{jam}) \times \mathrm{U}_{1}$

Pembantu Operator $(\mathrm{M}) \quad=(1$ orang/jam $) \times \mathrm{U}_{2}$

Sehingga total biaya operasi perjam adalah :

$$
\text { Biaya operasi : } \mathbf{P}=\mathbf{H}+\mathbf{I}+\mathbf{J}+\mathbf{K}+\mathbf{L}+\mathbf{M}
$$

\section{HASIL DAN PEMBAHASAN}

\section{Produksi Alat Berat dan Kebutuhan Alat Berat}

Tabel 1 merupakan rekapitulasi hasil produktivitas, jumlah kebutuhan alat berat, dan rencana durasi masing-masing alat berat pada tiga jenis pekerjaan berbeda disesuaikan dengan kondisi yang ada di lapangan. Produktivitas alat berat dipengaruhi oleh waktu siklus dan kecepatannya. Terkadang waktu siklus excavator mengalami masalah kondisi tanah yang susah digali sehingga waktu untuk memuat lebih lama. Volume pekerjaan dan produktivitas alat menentukan rencana durasi alat.

Tabel 1. Rekapitulasi Produksi Kerja Peralatan

\begin{tabular}{llllcc}
\hline \multicolumn{1}{c}{ Jenis Pekerjaan } & \multicolumn{2}{c}{$\begin{array}{c}\text { Volume } \\
\text { Pekerjaan }\left(\mathbf{m}^{\mathbf{3}}\right)\end{array}$} & \multicolumn{1}{c}{ Jenis Peralatan } & Produktivitas & $\begin{array}{c}\text { Jumlah Rencana Durasi } \\
\text { Alat (Hari) }\end{array}$ \\
\hline Galian struktur dengan & & Excavator & $17,778 \mathrm{~m}^{3} / \mathrm{jam}$ & 1 & 8 \\
kedalaman 2 - 4 meter & \multirow{2}{*}{010,88} & Dump Truck & $11,755 \mathrm{~m}^{3} / \mathrm{jam}$ & 2 & 8 \\
\hline Timbunan biasa dari & & Excavator & $30,521 \mathrm{~m}^{3} / \mathrm{jam}$ & 2 & 494 \\
sumber galian & \multirow{2}{*}{$240.773,20$} & Dump Truck & $13,171 \mathrm{~m}^{3} / \mathrm{jam}$ & 5 & 494 \\
& & Motor Grader & $1.839,780 \mathrm{~m} / \mathrm{jam}$ & 1 & 13 \\
& & Vibrator & $90,414 \mathrm{~m}^{2} / \mathrm{jam}$ & 1 & 333 \\
& & Roller Water Tanker & $71,142 \mathrm{~m}^{3} / \mathrm{jam}$ & 2 & 333 \\
\hline Penyiapan badan jalan & \multirow{2}{*}{$117.500,00$} & Motor Grader & $362,222 \mathrm{~m}^{2} / \mathrm{jam}$ & 1 & 41 \\
& & Vibrator & $126,851 \mathrm{~m}^{2} / \mathrm{jam}$ & 1 & 116 \\
& & Roller Water Tanker & $62,250 \mathrm{~m}^{3} / \mathrm{jam}$ & 3 & 116
\end{tabular}

(Sumber : hasil perhitungan analisis kapasitas produksi alat berat) 
Analisa Biaya Alat

Hasil perhitungan biaya per jam operasi dan biaya sewa per jam dari masing-masing alat yang ada di lapangan pada masing-masing item pekerjaan dapat dilihat pada tabel dibawah ini.

Tabel 2. Rekapitulasi BOK dan Biaya Sewa Alat Berat

\begin{tabular}{|c|c|c|c|c|c|}
\hline No. & Pekerjaan & Alat & $\begin{array}{c}\text { Jumlah } \\
\text { (unit) }\end{array}$ & $\begin{array}{l}\text { Bok per Jam } \\
\text { (Rp.) }\end{array}$ & $\begin{array}{c}\text { Biaya Sewa per } \\
\text { Jam (Rp.) }\end{array}$ \\
\hline \multirow[t]{2}{*}{1} & \multirow{2}{*}{$\begin{array}{l}\text { Galian struktur dengan } \\
\text { kedalaman 2-4 meter }\end{array}$} & Excavator & 1 & $718.048,581$ & $909.548,581$ \\
\hline & & Dump Truck & 2 & $1.658 .029,662$ & 1.882 .845 .042 \\
\hline \multirow[t]{5}{*}{2.} & \multirow{5}{*}{$\begin{array}{l}\text { Timbunan biasa dari } \\
\text { sumber galian }\end{array}$} & Excavator & 2 & $1.436 .097,162$ & $1.819 .097,162$ \\
\hline & & DumpTruk & 5 & $4.145 .074,155$ & $4.707 .112,605$ \\
\hline & & Motor Grader & 1 & $670.416,081$ & $879.908,581$ \\
\hline & & Vibrator & 1 & $609.423,907$ & $777.241,663$ \\
\hline & & $\begin{array}{l}\text { Roller Water } \\
\text { Tanker }\end{array}$ & 2 & $761.612,162$ & $832.576,25$ \\
\hline \multirow[t]{3}{*}{3.} & \multirow[t]{3}{*}{ Penyiapan badan jalan } & Motor Grader & 1 & $670.416,081$ & $879.908,581$ \\
\hline & & Vibrator & 1 & $609.423,907$ & $777.241,663$ \\
\hline & & $\begin{array}{l}\text { Roller Water } \\
\text { Tanker }\end{array}$ & 3 & $1.142 .418,243$ & $1.248 .864,375$ \\
\hline
\end{tabular}

(Sumber : hasil perhitungan analisis biaya operasional alat)

Perhitungan Pendapatan dan Profit

Tabel 3. Analisa Pendapatan dan Profit Alat Berat

Pada Pekerjaan Galian Struktur Kedalaman 2-4 meter

\begin{tabular}{|c|c|c|c|c|c|c|c|}
\hline $\begin{array}{c}\text { Jenis Alat } \\
\text { Alat }\end{array}$ & Jumlah & $\begin{array}{l}\text { Produksi } \\
\left(\mathrm{m}^{3} / \mathbf{j a m}\right)\end{array}$ & $\begin{array}{c}\text { Volume } \\
\left(\mathbf{m}^{3}\right)\end{array}$ & $\begin{array}{l}\text { Durasi } \\
\text { (jam) }\end{array}$ & $\begin{array}{c}\text { Biaya Sewa } \\
\text { Alat per Jam }(\text { Rp. })\end{array}$ & $\begin{array}{c}\text { Harga Satuan } \\
\text { Alat per } \mathbf{m}^{\mathbf{3}}(\mathbf{R p} .)\end{array}$ & $\begin{array}{c}\text { Jumlah } \\
\text { Biaya (Rp.) }\end{array}$ \\
\hline Excavator & 1 & 17,778 & $1.010,88$ & 64 & $909.584,581$ & $51.163,493$ & $58.213 .413,18$ \\
\hline Dump Truck & 2 & 23,51 & $1.010,88$ & 64 & $941.422,521$ & $70,466,26$ & $120.502 .082,7$ \\
\hline \multicolumn{4}{|c|}{ Jumlah Harga Peralatan } & \multicolumn{4}{|c|}{$178.715 .495,9$} \\
\hline \multicolumn{4}{|c|}{ PPN 10\% x Jumlah Harga Alat } & \multicolumn{4}{|c|}{$17.871 .549,59$} \\
\hline \multicolumn{4}{|c|}{ Jumlah Harga + PPN } & \multicolumn{4}{|c|}{$196.587 .045,5$} \\
\hline \multicolumn{4}{|c|}{ Profit $10 \%$ x (Jumlah Harga + PPN $)$} & \multicolumn{4}{|c|}{$19.658 .704,55$} \\
\hline \multicolumn{4}{|c|}{ Jumlah (Jumlah Harga + PPN + Profit) } & \multicolumn{4}{|c|}{216.245 .750} \\
\hline
\end{tabular}

Biaya Pekerjaan Tanah / Pendapatan

(Sumber : hasil perhitungan)

Berdasarkan hasil perhitungan diketahui produksi 1 unit excavator per jam adalah sebesar 17,778 $\mathrm{m}^{3} / \mathrm{jam}$ dengan volume pekerjaan 1.010,88 $\mathrm{m}^{3}$. Untuk 2 unit dump truck produksi per jam adalah 23,51 $\mathrm{m}^{3} /$ jam dengan volume pekerjaan $1.010,88 \mathrm{~m}^{3}$. Durasi (jam) kerja alat didapatkan dari hasil perkalian antara jumlah rencana durasi (hari) yang didapatkan dari hasil perhitungan dengan jam kerja dalam satu hari selama 8 jam. Sehingga untuk alat berat excavator dan dump truck dengan durasi 8 hari didapatkan 64 jam. Harga satuan alat per $\mathrm{m}^{3}$ dapat dihitung dengan mengalikan koefisien alat dan harga sewa alat dengan rumusan berdasarkan panduan analisis harga satuan Bina Marga, dimana koefisien alat didapat dari 1/produksi alat berat. Jumlah biaya peralatan alat berat didapatkan dari perkalian jumlah alat, durasi dan biaya sewa alat. Besar pendapatan dan profit dari penggunaan alat berat pada pekerjaan galian struktur dengan kedalaman 2-4 meter sebesar Rp. 216.245.750 dan Rp. 19.658.704,55.

Tabel 4. Analisa Pendapatan dan Profit Alat Berat Pada Pekerjaan Timbuan Biasa dari Sumber Galian

\begin{tabular}{|c|c|c|c|c|c|c|c|}
\hline $\begin{array}{c}\text { Jenis } \\
\text { Alat }\end{array}$ & $\begin{array}{c}\text { Jumlah } \\
\text { Alat }\end{array}$ & $\begin{array}{l}\text { Produksi } \\
\left(\mathbf{m}^{3} / J a m\right)\end{array}$ & Volume $\left(\mathbf{m}^{3}\right)$ & $\begin{array}{c}\text { Durasi } \\
\text { (Jam) }\end{array}$ & $\begin{array}{c}\text { Biaya Sewa } \\
\text { Alat Per Jam (Rp.) }\end{array}$ & $\begin{array}{c}\text { Harga Satuan } \\
\text { Alat Per } \mathbf{m}^{\mathbf{3}}(\mathbf{R p} .)\end{array}$ & $\begin{array}{c}\text { Jumlah Biaya } \\
\text { (Rp.) }\end{array}$ \\
\hline Excavator & 2 & 61,042 & $240.773,20$ & 3.952 & $909.584,581$ & $29.652,457$ & 7.189 .356 .528 \\
\hline Dump Truck & 5 & 65,855 & $240.773,20$ & 3.952 & $941.422,521$ & & 18.602 .509 .015 \\
\hline Motor Grader & 1 & $1.839,780$ & 240. & 104 & $879.908,581$ & 477,798 & $91.510 .492,42$ \\
\hline Vibrator Roller & 1 & 90,414 & $240.773,20$ & 2.664 & $777.241,663$ & $8.549,658$ & 2.070 .571 .790 \\
\hline Water Taker & 2 & 142,284 & $240.773,20$ & 2.664 & $416.288,125$ & $5.844,685$ & 2.217 .983 .130 \\
\hline
\end{tabular}




\begin{tabular}{ll}
\hline Jumlah Harga Peralatan & 30.171 .930 .955 \\
PPN 10\% X Jumlah Harga Alat & 3.017 .193 .096 \\
Jumlah Harga + PPN & 33.189 .124 .051 \\
Profit 10\% X (Jumlah Harga + PPN) & 3.318 .912 .405 \\
Jumlah (Jumlah Harga + Ppn + Profit) & 36.508 .036 .456 \\
Biaya Pekerjaan Tanah / Pendapatan & \\
\hline
\end{tabular}

Berdasarkan hasil perhitungan diketahui produksi 2 unit excavator per jam adalah sebesar 61,042 $\mathrm{m}^{3} / \mathrm{jam}$. Untuk 5 unit dump truck produksi per jam adalah $65,855 \mathrm{~m}^{3} / \mathrm{jam}$. 1 unit motor grader produksi per jam adalah 1.839,780 $\mathrm{m}^{3} / \mathrm{jam} .1$ unit vibrator roller produksi per jam adalah 90,414 $\mathrm{m}^{3} / \mathrm{jam} .2$ unit water tanker produksi per jam adalah 142,284 $\mathrm{m}^{3} / \mathrm{jam}$. Volume pekerjaan $240.773,20 \mathrm{~m}^{3}$. Durasi (jam) kerja alat didapatkan dari hasil perkalian antara jumlah rencana durasi (hari) yang didapatkan dari hasil perhitungan dengan jam kerja dalam satu hari selama 8 jam. Sehingga untuk alat berat excavator dan dump truck dengan durasi 494 hari didapatkan 3.952 jam. Untuk alat berat motor grader dengan durasi 13 hari didapatkan 104 jam. Untuk alat berat vibrator roller dan water tank dengan durasi 333 hari didapatkan 2.664 jam. Harga satuan alat per $\mathrm{m}^{3}$ dapat dihitung dengan mengalikan koefisien alat dan harga sewa alat dengan rumusan berdasarkan panduan analisis harga satuan Bina Marga, dimana koefisien alat didapat dari 1/produksi alat berat. Jumlah biaya peralatan alat berat didapatkan dari perkalian jumlah alat, durasi dan biaya sewa alat. Besar pendapatan dan profit dari penggunaan alat berat pada pekerjaan timbunan biasa dari sumber galian sebesar Rp. 36.508.036.456 dan Rp. 3.318.912.405.

\begin{tabular}{|c|c|c|c|c|c|c|}
\hline Jenis Alat & $\begin{array}{l}\text { Produksi } \\
\left(\mathbf{m}^{3} / \mathrm{Jam}\right)\end{array}$ & Volume $\left(\mathbf{m}^{3}\right)$ & $\begin{array}{l}\text { Durasi } \\
\text { (Jam) }\end{array}$ & $\begin{array}{l}\text { Biaya Sewa Alat } \\
\text { Per Jam (Rp.) }\end{array}$ & $\begin{array}{l}\text { Harga Satuan Alat } \\
\text { Per } \mathbf{m}^{\mathbf{3}}(\mathbf{R p} .)\end{array}$ & $\begin{array}{l}\text { Jumlah Biaya } \\
\text { (Rp.) }\end{array}$ \\
\hline Motor Grader & 362,222 & 117.500 & 328 & $879.908,581$ & $2.428,547$ & $288.610 .014,6$ \\
\hline Vibrator Roller & 126,851 & 117.500 & 928 & $777.241,663$ & $6.124,664$ & $721.280 .263,3$ \\
\hline Water Taker & 186,75 & 117.500 & 928 & $416.288,125$ & $4.454,282$ & 1.158 .946 .140 \\
\hline \multicolumn{3}{|c|}{ Jumlah Harga Peralatan } & \multicolumn{4}{|c|}{2.284 .731 .032} \\
\hline \multicolumn{3}{|c|}{ PPN $10 \%$ X Jumlah Harga Alat } & \multicolumn{4}{|c|}{$228.473 .103,2$} \\
\hline \multicolumn{3}{|c|}{ Jumlah Harga + PPN } & \multicolumn{4}{|c|}{ 2.513.204.135 } \\
\hline \multicolumn{3}{|c|}{ Profit $10 \%$ X (Jumlah Harga + PPN) } & 251.320 .41 & & & \\
\hline \multicolumn{3}{|c|}{ Jumlah Jumlah Harga + PPN + Profit } & 2.764.524.5 & & & \\
\hline
\end{tabular}

Berdasarkan hasil perhitungan diketahui produksi 1 unit motor grader per jam adalah 362,222 $\mathrm{m}^{3} / \mathrm{jam}$. 1 unit vibrator roller produksi per jam adalah 126,851 $\mathrm{m}^{3} / \mathrm{jam} .2$ unit water tanker produksi per jam adalah $186,75 \mathrm{~m}^{3} / \mathrm{jam}$. Volume pekerjaan $117.500 \mathrm{~m}^{3}$. Durasi (jam) kerja alat didapatkan dari hasil perkalian antara jumlah rencana durasi (hari) yang didapatkan dari hasil perhitungan dengan jam kerja dalam satu hari selama 8 jam. Sehingga untuk alat berat motor grader dengan durasi 41 hari didapatkan 328 jam. Untuk alat berat vibrator roller dan water tank dengan durasi 116 hari didapatkan 928 jam. Harga satuan alat per $\mathrm{m}^{3}$ dapat dihitung dengan mengalikan koefisien alat dan harga sewa alat dengan rumusan berdasarkan panduan analisis harga satuan Bina Marga, dimana koefisien alat didapat dari 1/produksi alat berat. Jumlah biaya peralatan alat berat didapatkan dari perkalian jumlah alat, durasi dan biaya sewa alat. Besar pendapatan dan profit dari penggunaan alat berat pada pekerjaan timbunan biasa dari sumber galian sebesar Rp. 2.764.524.549 dan Rp. 251.320.413,5.

Dari hasil analisa dan perhitungan diperoleh jumlah biaya pekerjaan / pendapatan pada pekerjaan tanah dengan hasil penjumlahan biaya pekerjaan setiap item pekerjaan didapatkan sejumlah Rp. 39.488.806.755 dengan profit sebesar Rp. 3.589.981.523,05. Sedangkan jumlah biaya pekerjaan tanah pada dokumen kontrak sebesar Rp. 50.042.724.892,12. Selisih biaya antara hasil pehitungan dengan nilai kontrak sebesar Rp. 10.553.918.137,12. Selisih biaya ini diindikasikan dapat terjadi karena kebutuhan jumlah alat yang diperoleh pada hasil perhitungan berbeda dengan jumlah alat yang digunakan serta tidak dilakukan perhitungan produktivitas dan biaya operasional untuk pekerjaan pembersihan dan pengupasan lahan. Durasi pekerjaan tanah yang diperoleh dari hasil perhitungan adalah selama 494 hari atau setara dengan 16 bulan, sedangkan durasi pekerjaan tanah yang tertera dalam dokumen kontrak adalah 18 bulan. Hal ini dapat terjadi karena penambahan jumlah alat berat excavator pada pekerjaan timbunan biasa dari sumber galian. Penambahan jumlah alat dilakukan untuk mengefiensikan biaya dan durasi pekerjaan. 


\section{PENUTUP}

\section{Simpulan}

Berdasarkan hasil perhitungan dan pembahasan, maka dapat dibuat kesimpulan sebagai berikut :

1. Alat berat yang digunakan pada pekerjaan tanah adalah excavator merek caterpillar, dump truck merek hino, motor grader merek komatsu, vibrator roller merek caterpillar, water tanker truck merek hino.

2. Produksi alat berat yang dihitung merupakan produksi nyata di lapangan. Produksi yang dihasilkan pada pekerjaan galian struktur dengan kedalaman 2-4 meter yaitu excavator sebesar 17,778 $\mathrm{m}^{3} / \mathrm{jam}$ dan dump truck sebesar $11,755 \mathrm{~m}^{3} / \mathrm{jam}$. Untuk pekerjaan timbunan biasa dari sumber galian produksi yang dihasilkan oleh excavator sebesar $30,521 \mathrm{~m}^{3} / \mathrm{jam}$, dump truck sebesar $13,171 \mathrm{~m}^{3} / \mathrm{jam}$, motor grader sebesar $1.839,780 \mathrm{~m}^{3} / \mathrm{jam}$, vibrator roller sebesar $90,414 \mathrm{~m}^{3} / \mathrm{jam}$ dan water tanker truck sebesar 71,142 $\mathrm{m}^{3} / \mathrm{jam}$. Sedangkan untuk pekerjaan penyiapan badan jalan produksi yang dihasilkan oleh motor grader sebesar $362,222 \mathrm{~m}^{3} / \mathrm{jam}$, vibrator roller sebesar $126,851 \mathrm{~m}^{3} / \mathrm{jam}$ dan water tanker truck sebesar 62,250 $\mathrm{m}^{3} / \mathrm{jam}$.

3. Kebutuhan alat berat pada proyek sirkuit mandalika khususnya pada pekerjaan tanah, yaitu pekerjaan galian struktur kedalaman 2-4 meter sejumlah 1 unit excavator dan 2 unit dump truck. Untuk pekerjaan timbunan biasa dari sumber galian sejumlah 2 unit excavator, 5 unit dump truck, 1 unit motor grader, 1 unit vibrator roller, dan 2 unit water tanker truck. Sedangkan untuk pekerjaan penyiapan badan jalan sejumlah 1 unit motor grader, 1 unit vibrator roller, dan 3 unit water tanker truck.

4. Biaya operasi per jam dan total biaya sewa per jam yang didapatkan dari hasil perhitungan untuk alat berat excavator masing-masing sebesar Rp. 718.048,581 dan Rp. 909.548,581. Dump truck sebesar Rp. 829.014,831 dan Rp. 941.422,521. Untuk alat berat motor grader didapatkan biaya operasi per jam dan biaya sewa per jam masing-masing sebesar Rp. 670.416,081 dan Rp. 879.908,581. Vibrator roller sebesar Rp. 609.423,907 dan Rp. 777.241,663. Sedangkan untuk water tanker truck diperoleh biaya operasi dan biaya sewa per jam masing-masing sebesar Rp. 380.806,081 dan Rp 416.288,125.

5. Pendapatan dan profit yang didapatkan dari penggunaan alat berat pada pekerjaan galian struktur kedalaman 2-4 meter adalah Rp. 216.245.750 dan Rp. 19.658.704,55. Untuk penggunaan alat berat pada pekerjaan timbunan biasa dari sumber galian didapatkan pendapatan dan profit masing-masing sebesar Rp. 36.508.036.456 dan Rp. 3.318.912.405. Sedangkan untuk penggunaan alat berat pada pekerjaan penyiapan badan jalan diperoleh pendapatan dan profit masing-masing sebesar Rp. 2.764.524.549 dan Rp. 251.320.413,5.

\section{Saran}

Berdasarkan kesimpulan diatas, maka dapat dikemukakan saran sebagai berikut :

1. Pemilihan alat berat yang akan digunakan pada pekerjaan tanah harus sesuai dengan volume dan waktu yang telah ditentukan baik dalam segi pemilihan jenis alat, tipe alat, dan jumlah alat agar dalam suatu pekerjaan tidak mengalami kerugian.

2. Sebelum pelaksanaan pekerjaan dimulai agar dilaksanakan rapat teknis untuk menyatukan persepsi agar diperoleh hasil yang maksimal.

3. Sebaiknya di dalam operasional alat- alat berat perlu adanya pengawasan yang ketat terhadap kerja operator disamping itu juga pengecekan alat setelah beroperasi agar alat tetap dalam kondisi baik sehingga tidak menggangu jadwal pekerjaan yang telah ditentukan didalam perencanaan semula.

4. Sebaiknya dilakukan analisis perhitungan pemilihan alternatif alat-alat berat agar durasi waktu tepat dan biaya yang dibutuhkan sesuai dengan pelaksanaan pekerjaan masing-masing.

\section{DAFTAR PUSTAKA}

Caterpillar inc. (2012). Caterpillar Performance Handbook $42^{\text {th }}$ Edition. Illinois USA: Caterpillar inc. Komatsu Ltd. (2006). Spesification and Application Handbook $27^{\text {th }}$ Edition. Japan.

Rochmanhadi. (1982). Alat berat dan Penggunaannya. Jakarta: Departemen Pekerjaan Umum

Rostiyanti, SF. (2002). Alat Berat Untuk Proyek Konstruksi. Jakarta: Penerbit Rineka Cipta

Wilopo, Djoko. (2009). Metode Konstruksi dan Alat-alat Berat. Jakarta: Universitas Indonesia 